\title{
Atypical Progress of Primary Undiagnosed Hepatoblastoma Romaniuk $A^{1}$, Piddubnyi $A^{2}$, Sikora $V^{3}$
}

\begin{abstract}
:
Introduction: Hepatoblastoma is a disease that has a variety of clinical manifestations. This fact complicates the diagnosis of a large number of cases of this disease. Case presentation: A 64-year-old female Ukrainian patient was admitted to the anesthesiology and reanimation department in critical condition with a diagnosis: dissecting abdominal aortic aneurysm. Despite to the complex of treatment and diagnostic measures after 10 hours was established a biological death. At autopsy of the patient were detected changes that characteristic for hepatoblastoma. Histological examination of the liver revealed the next diagnosis: poorly differentiated hepatocellular liver cancer. Conclusions: The patient had non-typical progress of the hepatoblastoma, which led to the erroneous diagnosis and incorrect chosen of the treatment strategy.
\end{abstract}

Keywords: hepatoblastoma; atypical progress; hepatocellular cancer; erroneous diagnosis

Bangladesh Journal of Medical Science Vol. 15 No. 02 April'16. Page : 292-296

\section{Introduction}

Hepatocellular liver cancer (HLC) is a malignant tumor, that develops from hepatocytes. The most important etiological factors of this disease include infectious agents (viral hepatitis B and C), chronic alcoholism (consumption of more than 50 grams per day, in alcohol equivalent), metabolic disorders (hereditary hemochromatosis, tyrosinemia, Wilson's disease, deficiency of alpha-one-antitrypsin), the use of drugs and toxins (aflatoxin B, androgens, progestogens, thorium dioxide), cirrhosis, etc [2]. It was also investigated the relationship of liver cancer with the usage of xenobiotics, such as organochlorine pesticides, polychlorinated biphenyls and vinyl chlorides [6].

HLC ranks the fifth place among the structure of malignant tumor and the third place among the causes of death. [6]. According to the WHO, this pathology is often found among people of South Africa, Asia, North and South America, North Europe, where the incidence can range from 21.1 [2] to 30 [3] per 100000 population. Analysis of the reproductive structure of morbidity indicates the major lesion of men, than women $(7.4 \%$ and
$3.2 \%$ according to all the malignancies) [2].

In the majority of patients HLC is asymptomatic or accompanied by pain, weight loss, bleeding, fever, malaise, ascites, sub- and icteric of the skin and mucous membranes, the presence of distant and regional metastases $[3,6]$.

For intravital diagnosis one uses ultrasound examination, magnetic resonance tomography, computed tomography, scintigraphy, biopsy research, determination of the alpha-fetoprotein in blood. The high level of the alpha-fetoprotein ( $>$ $1000 \mathrm{ng} / \mathrm{mL}$ ) is found in $2 / 3$ patients with HLC $[3]$.

At the autopsy HLC manifests in the form of single or multiple soft, yellow-green or mottled nodes of different forms and sizes (diameter from 0.5 to $15 \mathrm{~cm}$ ) [3]. According to the type of growth one allocates multinodular, single-nodular and diffuse forms of the HLC [6].

\section{Case presentation}

A 64-year-old female Ukrainian patient was admitted to the anesthesiology and reanimation department with complaints of pain in all the parts of the abdomen, lumbar pain, general weakness, nausea.

1. Anatolii Romaniuk, prof., head of pathology department. Sumy State University, department of pathology, Ukraine.

2. Artem Piddubnyi, student. Sumy State University, department of pathology, Ukraine.

3. Vladyslav Sikora, student. Sumy State University, department of pathology, Ukraine.

Corresponds to: Artem Piddubnyi, student, Ukraine, c. Sumy, st. Privokzalna, 31, Postal code: 40022, E-mail: a.piddubny@med.sumdu.edu.ua 


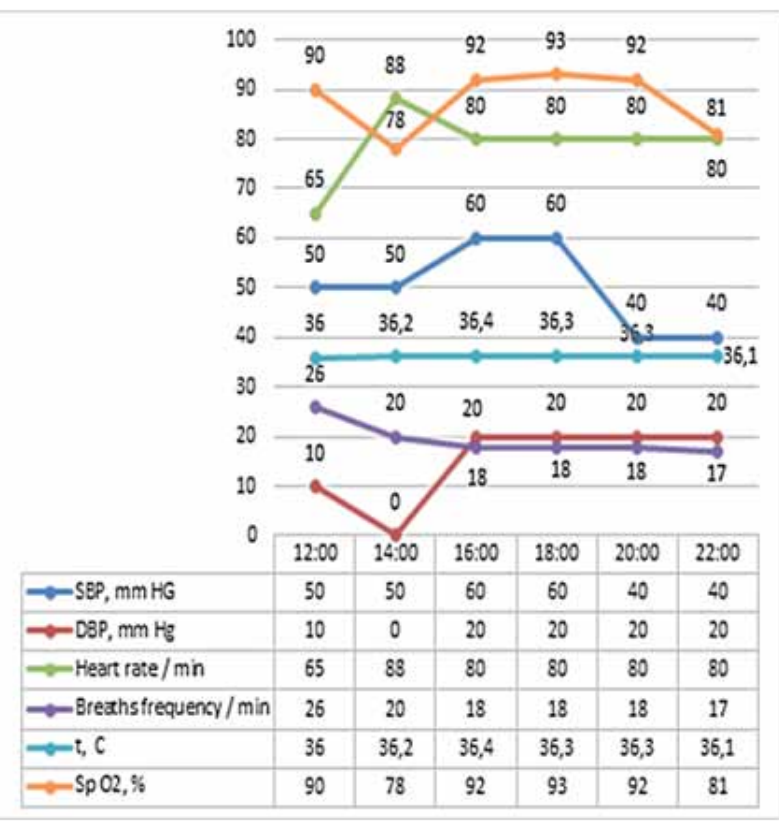

Fig. 1.Vital importance parameters of the patient in dynamics.

From anamnesis we know that the patient has felt discomfort in the right upper quadrant for about 4 days. On the eve patient was consulted by urologist and general surgeon because of overall health deteriorating. Urgent surgical and urological pathologies at the time of inspection were not found. The patient has had rheumatoid arthritis for 17

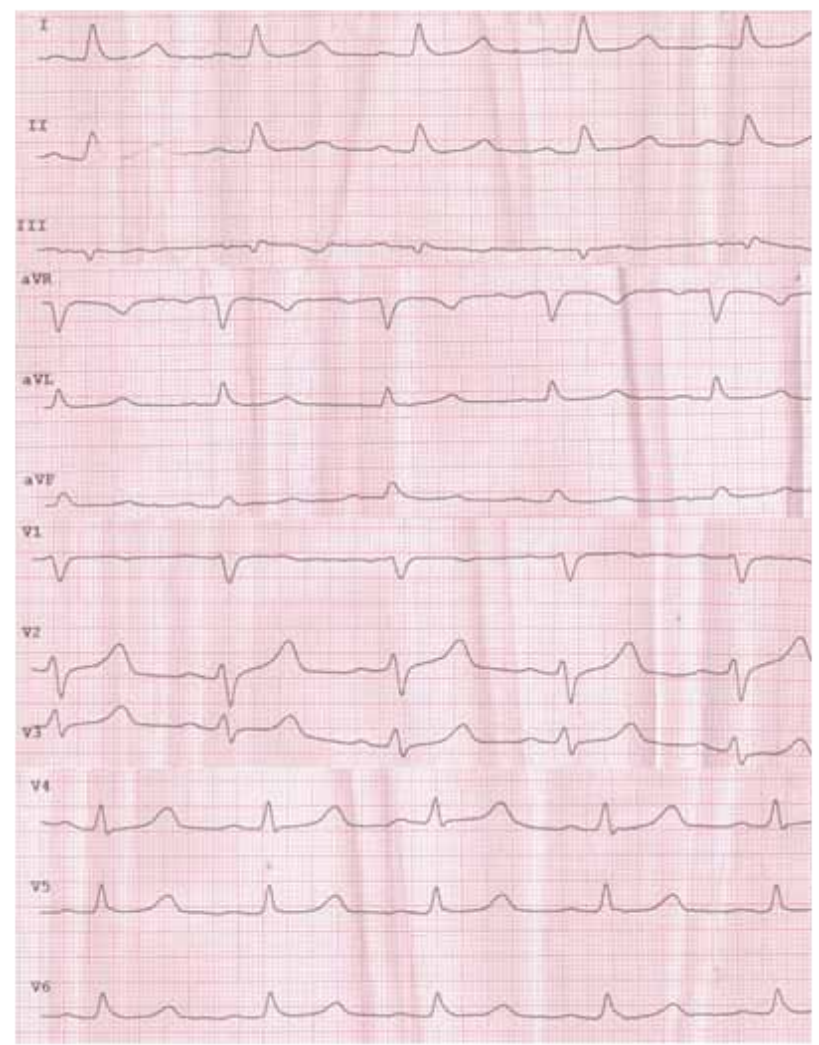

Fig. 2.Electrocardiogram of the patient. $10 \mathrm{~mm} /$ $\mathrm{mV}, 50 \mathrm{~mm} / \mathrm{s}, \mathrm{F} 50 \mathrm{~Hz}, \mathrm{~F} 35$ years and has regularly taken NSAIDs. She was operated on about fibromyoma 16 years ago, suffered from hypertension, received treatment repeatedly because of atherosclerosis, but she did not receive a systemic therapy.

When the patient was admitted to the hospital, she had a broken mind (stupor type), a slurred speech, a pale-pink skin, arterial pressure was $25 / 0 \mathrm{~mm} \mathrm{Hg}$, heart rate was $100 / \mathrm{min}$, a frequency of breathing movements was 20 per minute, oxygen saturation was of $90 \%$. The level of total bilirubin was to $89.31 \mathrm{mmol} / 1$ (22.3 mmol/1 - direct and 67.01 $\mathrm{mmol} / \mathrm{l}$ - indirect fractions), total cholesterol - 11.2 $\mathrm{mmol} / \mathrm{l}$ (HDL - $1.42 \mathrm{mmol} / \mathrm{l}$, LDL - $8.14 \mathrm{mmol} / \mathrm{l}$, TG-1.64 mmol/1, IA - 6.89), total protein $68.4 \mathrm{~g}$ $/ 1$ (albumins - 54,1\%, $\alpha 1$-globulins - 4,6\%, $\alpha 2$ globulins - $8.3 \%, \beta$-globulins - 19,9\%, $\gamma$-globulins $-13.1 \%)$.

Based on the data from anamnesis, laboratory results and ultrasound examination of the abdomen (conclusion: in the projection of the abdominal aorta there was revealed a formation of $120 \mathrm{x}$ $70 \mathrm{~mm}$ irregular shape with a wall thickness of $15 \mathrm{~mm}$ ), the negative dynamics of clinical blood parameters (Tab. 1), hemodynamics and other important parameters (Fig. 1) it was diagnosed: Dissecting abdominal aortic aneurysm.

For the differential diagnosis with acute coronary syndrome there was made an electrocardiographic research (Fig. 2).

The patient received a medical treatment: infusion therapy of plasma substitutes $(\mathrm{NaCl} 0,9 \% 200 \mathrm{ml}$ 1 time per day, Ringer's solution $200 \mathrm{ml} 1$ time per day, 5\% glucose solution $200 \mathrm{ml} 1$ time per day, $6 \%$ hydroethyl-amylum $400 \mathrm{ml}$ time per day, $8 \%$ gelatin polysuccinate $200 \mathrm{ml} 1$ time per day), antibiotics (ceftazidime 1.02 time per day), steroid hormones (dexamethasone 0.016 per day), catecholamine hormones (4\% dopamine $10 \mathrm{ml}$ per day, $0.1 \%$ epinephrine $6 \mathrm{ml})$.

After 10 hours despite the medical therapy there was established a biological death. At the autopsy abdominal and pleural cavity was free, without adhesions. Lungs were with edema, pink foamy liquid ran on the cut (Fig. 3 - E). Bronchial mucosa had a pink color. Size of the heart was $12 \times 10 \times 5,5 \mathrm{~cm}$, with signs of obesity, small and large focal areas of cardiosclerosis, concentric hypertrophy of myocardial, fibrotic changes of valvular, especially mitral(Fig. 3 - F). Coronary artery was winding, with signs of atherosclerosis, unevenly calcified. The aorta was with pronounced 
Table 1. Parametersofthe blood.

\begin{tabular}{|c|c|c|c|c|}
\hline & $\begin{array}{c}04 / 05 / 2015 \\
, 20^{00}\end{array}$ & $\begin{array}{c}05 / 05 / 2015 \\
, 12^{00}\end{array}$ & $\begin{array}{c}05 / 05 / 2015 \\
, 18^{00}\end{array}$ & $\begin{array}{c}05 / 05 / 2015 \\
21^{30}\end{array}$ \\
\hline Hemoglobin, g/L & 120 & 81 & 77 & 55 \\
\hline Erythrocytes, (×1012) & 4,06 & 2,6 & 2,42 & 2,13 \\
\hline Colourindicator & 0,95 & 0,93 & 0,91 & 0,83 \\
\hline White blood cells, 10\%/ L & 43 & 31 & 22 & 17 \\
\hline - Eosinophils, \% & 0 & 0 & 0 & 0 \\
\hline - Basophils, \% & 0 & 1 & 1 & 0 \\
\hline - Myelocyte, \% & 0 & 1 & 3 & 1 \\
\hline - Juvenileneutrophils, \% & 0 & 0 & 1 & 1 \\
\hline - Nonfilamentedneutrophils, \% & 22 & 23 & 26 & 24 \\
\hline - Filamentedneutrophil, \% & 67 & 62 & 56 & 63 \\
\hline - Lymphocytes, \% & 6 & 6 & 7 & 5 \\
\hline - Monocytes, \% & 5 & 7 & 6 & 6 \\
\hline Thrombocytes, 10\% $/$ л & 192,6 & 180,4 & 137,94 & 117,54 \\
\hline ESR,mm / h & 12 & 12 & 14 & 15 \\
\hline
\end{tabular}

symptoms of atherosclerosis and atherocalcinosis, had a single small erosion and was smoothed and aneurysms were not found. Mucosa of the stomach pale. Intestinal mucosa was hyperemic, folding
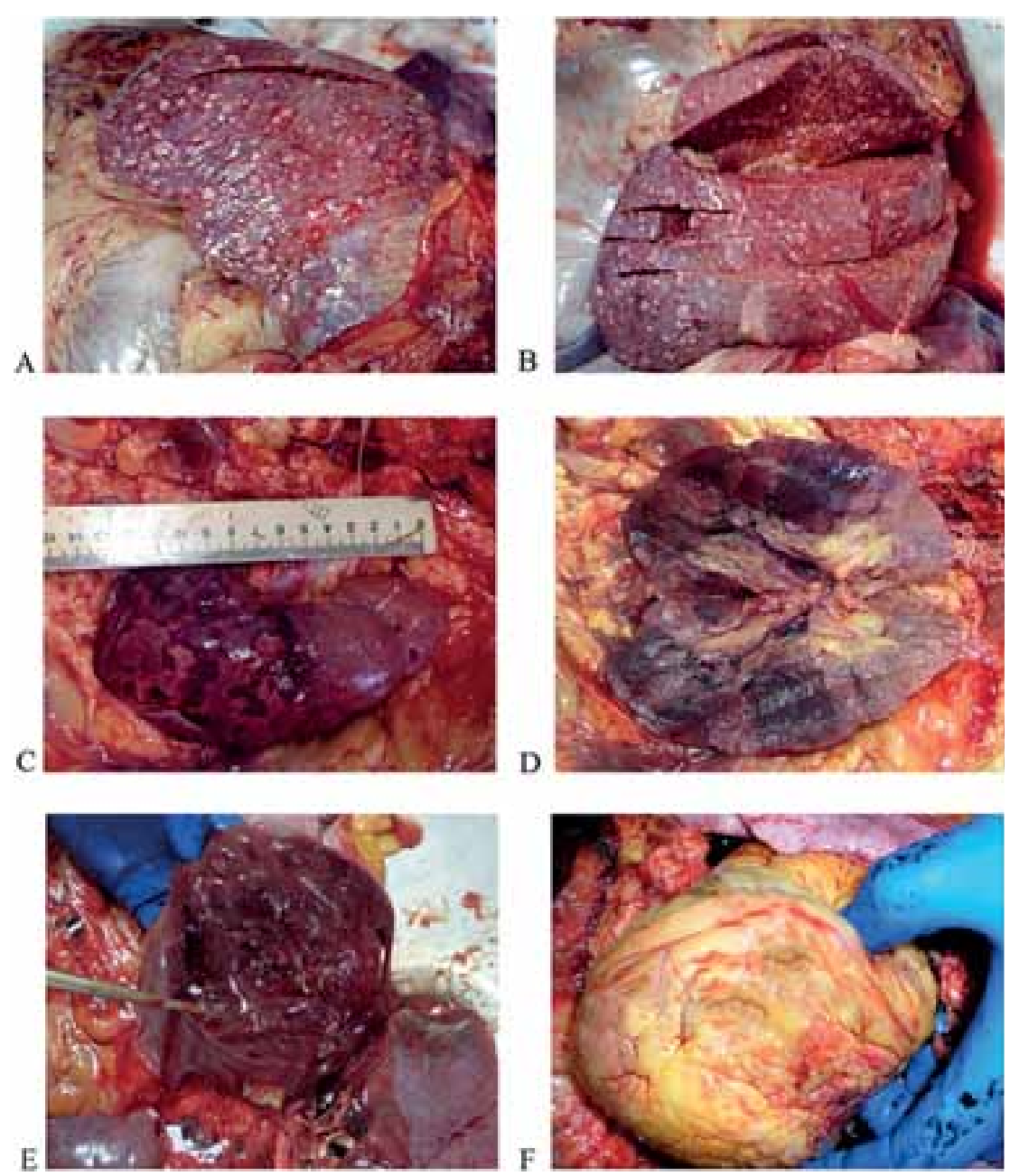

Fig. 3. Autopsy of patient: Liver: A - organ surface; B - internal structure. Right kidney: C - appearance; D - surface cut. Lungs: E - surface cut.Heart: F - organ surface. was saved. Examination of liver drew the attention because of its enlarged size $(31 \times 20 \times 17 \times 15 \mathrm{~cm})$, tuberosity of the surface, multiple formations in the blood vessels and bile ducts of whitish-yellow color, that had a diameter of $2 \mathrm{~cm}$, fuzzy contour, soft texture and a tendency to germinate. These nodal formations were evenly distributed throughout the liver parenchyma, were surrounded by small hemorrhages at liver tissue (Fig. 3 - A, 3 - B).

The left kidney was small $(9 \times 4 \times 3,5 \mathrm{~cm})$, with signs of fatty degeneration. The right kidney was increased $(15 \times 9 \times 7 \mathrm{~cm})$, with a mottled surface (Fig. 3 - C) large mottled kidney), on the incision - with signs of obesity and blood supply disorders - infarcts (Fig. 3 - D). The mucous membrane of the renal pelvis had a grayish-red color and the ureters were cyanoticpale (Fig. 3 - D). The spleen was enlarged $(18 \times 9 \times 7 \mathrm{~cm})$ and had a soft consistency. Internal female genital organs were missing. With the further research we didn't find metastases in other 

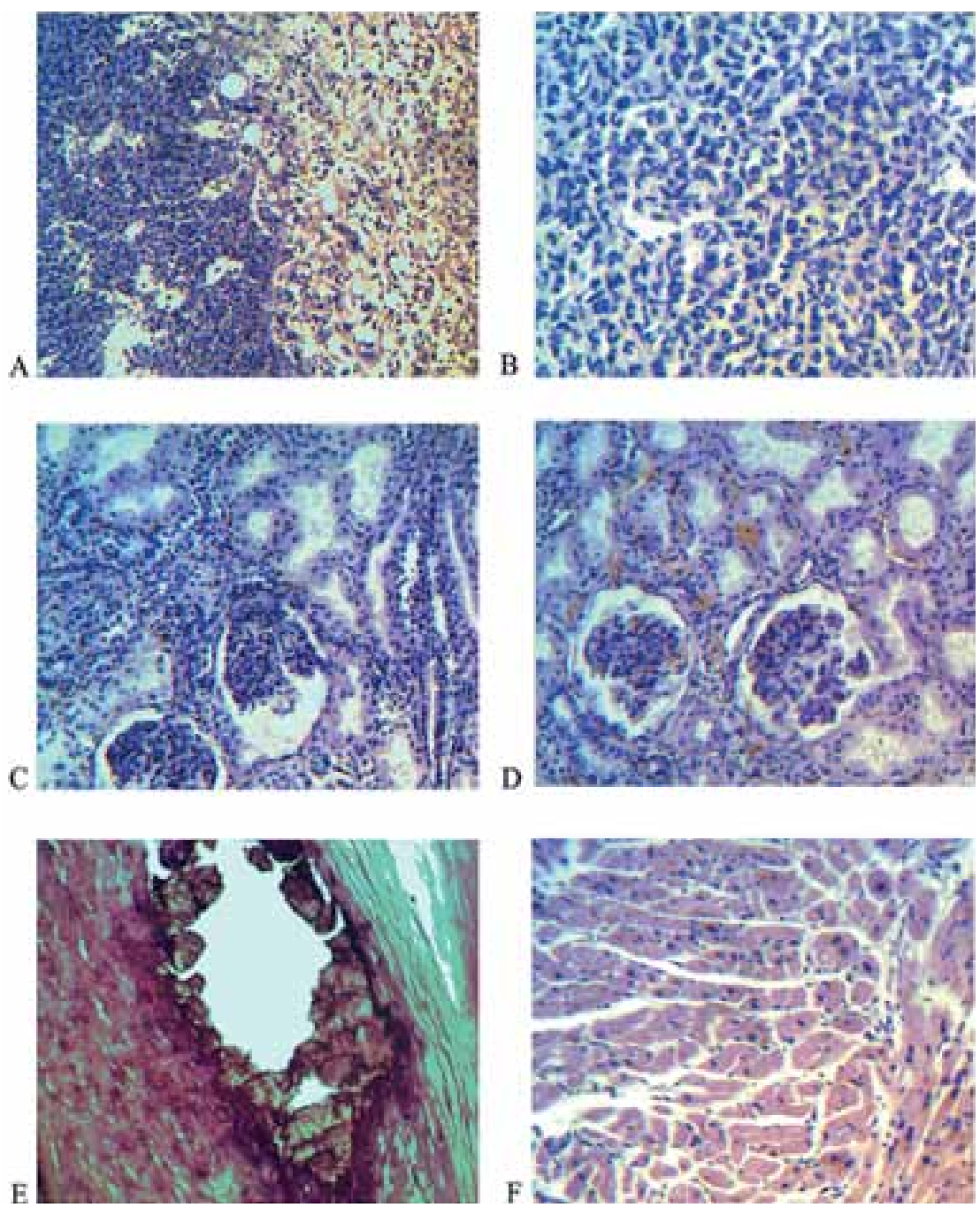

Fig. 4. Histologicalexaminationofthe liver,kidneys, aortaandheart.

Stainingbyhematoxylin - eosin. A. Liverzoom $\times 150 ; B$. Liverzoom $\times 400 ;$ C. Leftkidneyzoom $\times 150 ;$ D. Rightkidneyzoom $\times 150 ;$ E. Aorta zoom $\times 400$; F. Heart zoom $\times 150$.

organs.

Histological examination revealed that the formations in liver tissue were atypical hepatocytes with a high mitotic index. Architectonics of the organ was broken, tumor cells had round or irregular polygonal forms and exaggerated the size of typical hepatocytes (1.5-2 times), also, they were with a high nuclear-cytoplasmic index, had a basophilic cytoplasm with fatty and granular inclusions. The nuclei had a round or irregular shape and were hyperchromic, optically - uniform. In the preparation there were optically empty vessels and bile ducts in the portal areas. Many cells were presented by atypical hepatocytes with several ( 2 to 5 ) nuclei of different size, abnormal mitosis. According to the results of the histological examination it was determined that the tumor belonged to poorly differentiated HLC (Fig. 4 - A, 4 - B).

Histological examination of the kidneys revealed that the right kidney was hypertrophied with the phenomena of pyramids blood seepage and cortex substance of the organ, perivascular edema, vessels hyperemia (Fig. 4 - C, 4 - D). In the wall of the aorta there was revealed a deposit of calcium salts, proliferation of connective tissue, degradation of elastic fibers (Fig. 4 - E). Also, the myocardial research showed the hypertrophy of cardiomyocytes (Fig. 4 - F).

\section{Discussion}

HLC is a polyetiological disease, which can clinically show a variety of symptoms - from asthenic-vegetative syndrome to the symptoms of hepatocellular insufficiency. There is a problem of early diagnosis and a treatment of this disease. Literature data about the similarity of clinical symptoms of HLC progress and dissecting aneurysm in abdominal part of aortic are absent.

A 64-year-old female Ukrainian patient was admitted to the anesthesiology and reanimation department, where a multinodular form of low differentiated HLC was found. A clinical picture of this pathology in this case resembled the symptoms of dissecting aneurysm in abdominal part of aortic. The possibility of aortic lesions testified -an advanced age of the patient, a female sex, atherosclerotic, hypertensive, rheumatic anamnesis and also the results of additional research methods, including ultrasound of the abdomen, the deterioration of the blood pressure dynamics and clinical blood indicators. Despite the complex diagnostic and therapeutic manipulation - treatment of the patient was without a positive result.

The lethal result was caused by the extremely difficult general condition of the patient, the late stage of the disease, insufficiency and inaccuracy of the diagnostics and, as a result, an incorrectly chosen treatment. 


\section{Conclusions}

The clinical course of hepatoblastoma was accompanied by non-typical signs of liver disease.

A non-typical course of the disease led to the erroneous diagnosis: dissecting abdominal aortic aneurysm.

An ultrasound lifetime picture of morphological changes in the patient was assessed incorrectly, causing the discrepancy between the clinical and final posthumous diagnosis.

\section{Consent}

Written informed consent was obtained from the patient's next of kin for publication of this case report and any accompanying images.

\section{Competing interests}

The authors declare that they have no competing interests.

\section{Authors' contributions}

AR was responsible for final approval of the article, analysis and interpretation of the data. AP and VS were involved in the writing of the manuscript. $\mathrm{AR}, \mathrm{AP}$ and VS participated in writing and editing the manuscript. AP and VS performed the autopsy and anatomopathological evaluation. All authors read and approved the final manuscript.

\section{Acknowledgements}

We thank Zolotarova Vera who helped in the conduction of histochemical reactions.

Conflict of interest: None

\section{References:}

1. Bossone E, Suzuki T, Eagle KA. Diagnosis of acute aortic syndromes: imaging and beyond. Herz. 2013, 38 (3): 269-76.

2. Bosman F.T., Carneiro F., Hruban R.H. World Health Organization Classification of Tumours. Pathology and Genetics of Tumours of the Digestive System. Lyon: IARC Press; 2010.

3. Christopher D.M. Fletcher. Diagnostic histopathology of tumors. 4th ed. 2013.

4. El-Serag HB, Marrero JA, Rudolph L. Diagnosis and treatment of hepatocellular carcinoma. Gastroenterology. 2008; 134 (6): 1752-63.

5. Ertle JM, Heider D, Wichert M, Keller B. A combination of $\alpha$-fetoprotein and des- $\gamma$-carboxy prothrombin is superior in detection of hepatocellular carcinoma. Digestion. 2013; 87 (2): 121-31.

6. Liang Cheng, David G. Bostwick. Essentials of Anatomic Pathology. 3rd ed. 2011.

7. Tateishi R, Shiina S, Teratani T. Percutaneous radiofrequency ablation for hepatocellular carcinoma. An analysis of 1000 cases." Cancer. 2005; 103 (6): 1201-9.

8. White DL, Kanwal F, El-Serag HB. Association between nonalcoholic fatty liver disease and risk for hepatocellular cancer, based on systematic review. Clinical gastroenterology and hepatology. 2012; 10 (12): 1342-59. 